\title{
Tetting Your Community Involved With Collection Building
}

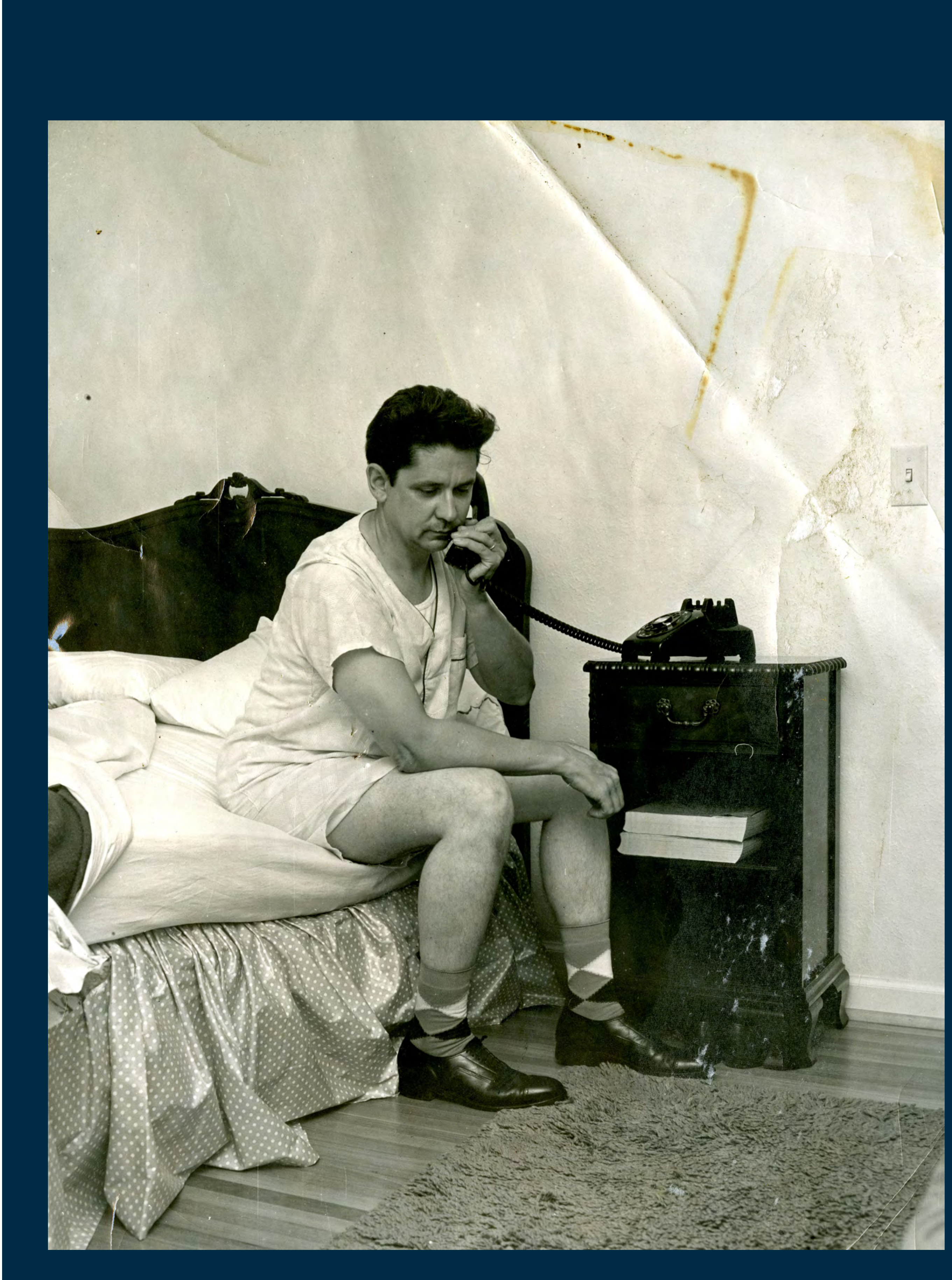

Courtesy Toledo Edison Company | CPA-2018-00127

\begin{abstract}
Overview of Initiative The purpose of the Community Photo Album (CPA) is to generate a pathway by which the public is directly able to contribute to Local History and Genealogy collections, unmitigated by library staff biases, in order to democratize the process of collection building. Both analog and digital images accepted.
\end{abstract}

\section{Metadata}

Description: To ensure submitters are able to represent their images in as authentic a voice as possible, descriptions are copied verbatim from the submission form. Only in rare occasions is any light editing done to correct obvious typing mistakes that might cause confusion to the viewer.

Subjects: A controlled vocabulary was established to sort all submissions into; this has been expanded as new terms were needed. The subject headings fall into two categories: general topics (e.g. Buildings / Calamities / Families / Portraits) and specific entities (e.g. Imagination Station / Maumee River / Toledo Metroparks / University of Toledo)

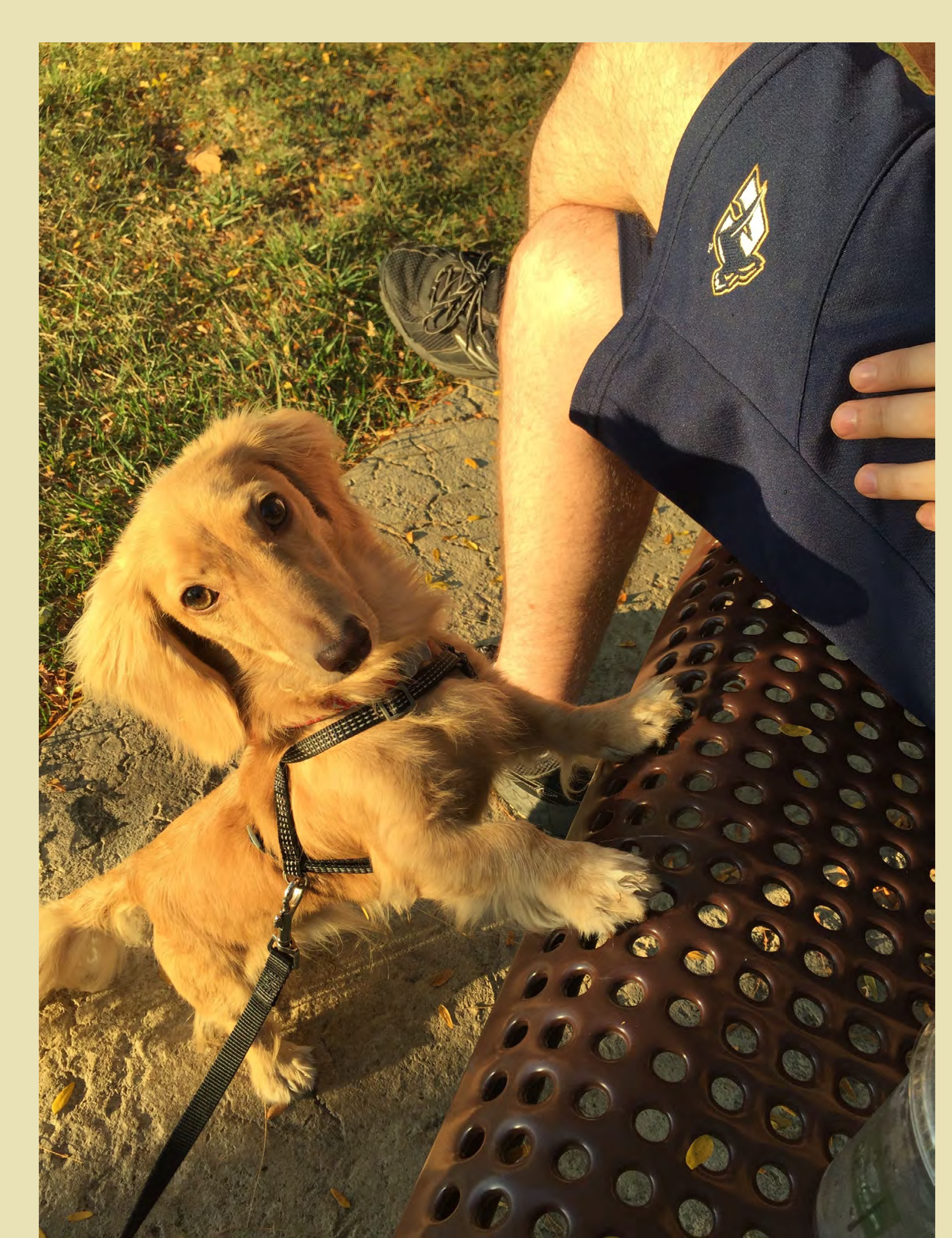

Courtesy Christina Gaydos | CPA-2019-00611

\section{Legal Agreement}

"The Toledo Lucas County Public Library (TLCPL) would like to preserve the heritage of Toledo, Lucas County, and Northwest Ohio by asking our customers to provide digital still images taken in the area for us to make available online for the community to view in our Community Photo Album. This is being done to create a photographic record of our geographic area both for the enjoyment of the community in the present, and the preservation of our history for the future. Our customers ensure that they either own the copyright for these images, or have permission to share them with us. Our customer also grants to TLCPL a non-exclusive license to share the images in our Community Photo Album in perpetuity. This means that the customer still owns the copyright on the images, but you will allow the library to use those images forever for non-commercial purposes. TLCPL does reserve the right to assess all submissions, and can reject any images from being included in the Community Photo Album."

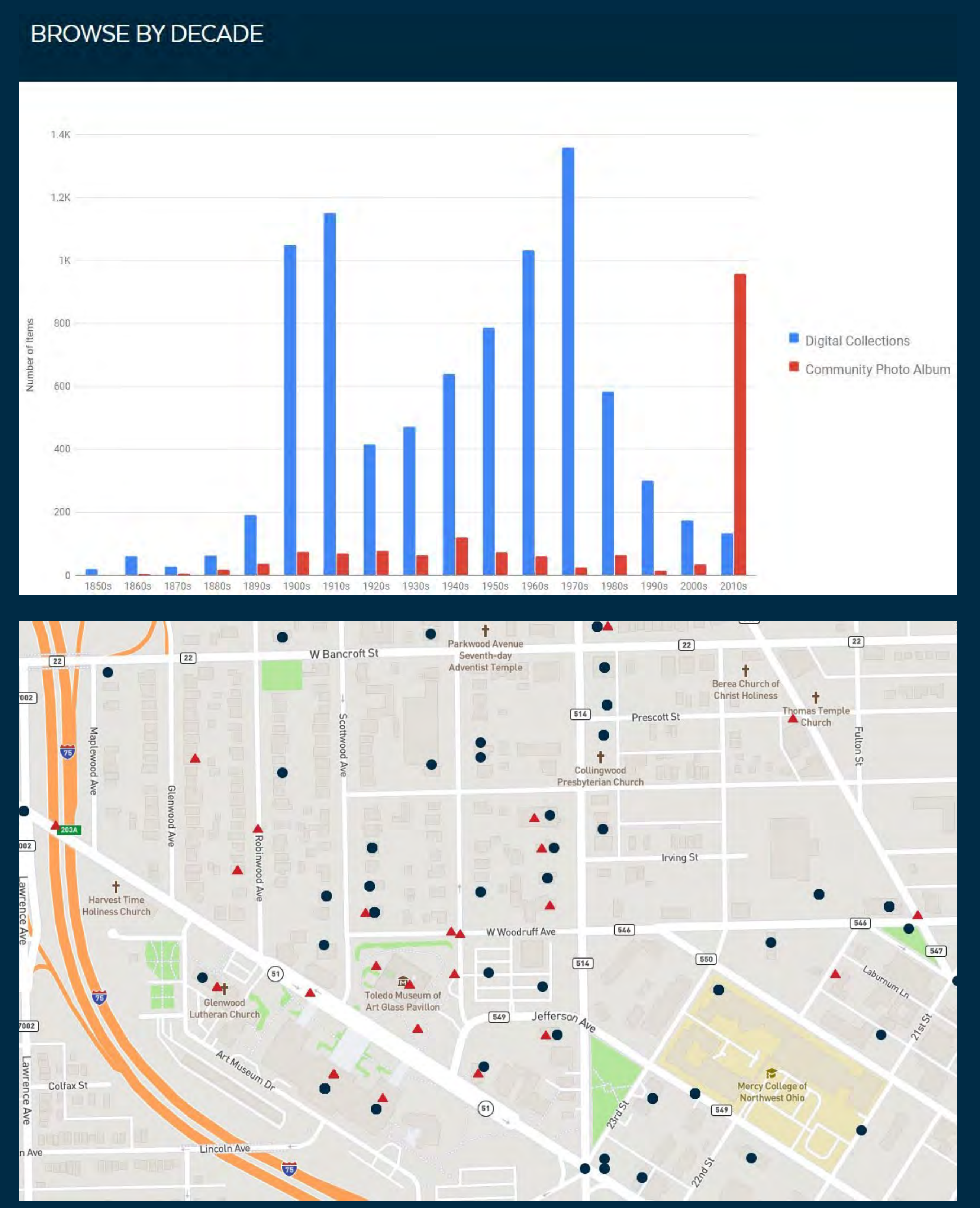

\section{Access}

Access to the CPA is accomplished through a dedicated collection in Ohio Memory (powered by CONTENTdm), as well as inclusion in the Library's federated search tool for digital collections.

Temporal and geospatial data visualizations have also been created that provide a timeline and map-based view of the contents of the collections. The CPA is represented by the red columns and red triangles respectively.

Society of Ohio Archivists, 2020 Meeting John Dewees, MLIS Toledo Lucas County Public Library 